\title{
COCONUT HUSK CHAR BIOSORPTIVITY IN HEAVY METAL DIMINUTION FROM CONTAMINATED SURFACE WATER
}

\author{
AJAYI-BANJI ADEMOLA ${ }^{* 1}$, SANGODOYIN ABIMBOLA ${ }^{2}$, IJAOLA OPOLOLA ${ }^{2}$ \\ ${ }^{1}$ Agricultural and Biosystems Engineering Department, Faculty of Engineering and \\ Technology, University of Ilorin, Ilorin, Nigeria \\ ${ }^{2}$ Agricultural and Environmental Engineering Department, Faculty of Technology, \\ University of Ibadan, Ibadan, Nigeria
}

\begin{abstract}
Applicability of coconut husk char in heavy metal removal was examined in the study. The surface morphology and elemental compositions of the char was investigated with SEM-EDX machine. Heavy metals sorption on $100 \mathrm{~g}$ of the char dosage was studied under five different contact times in the column experiment. Isotherm and kinetic models were the probing tools for biosorption mechanism prediction. Results indicated removal efficiency for chromium, cobalt, cadmium, aluminum and arsenic at 60 mins contact time were $72,80,86,89$ and $100 \%$ respectively. Contaminate removal depends on metal involved and sorption contact time. Adsorption data are fitted well into Freundlich isotherm model $\left(\mathrm{R}^{2}>0.92\right)$. Pseudo kinetic second order well described the adsorption process, with most $R^{2}$ values $\geq 0.94$. Coconut husk char is an effective biosorbent in sequestration of arsenic, cadmium, aluminum and cobalt in contaminated surface water.
\end{abstract}

Keywords: coconut husk char, removal efficiency, isotherm models, pseudo kinetics

\section{INTRODUCTION}

Technological advancement pivotal to development has enhanced the utilization of several materials in the production line. The materials principal in the alleviation of societal needs are plastic, steel, iron, rubber, fiber, paper and timber. Use of any type of the materials in the production industries varies with the nature of work, financial resources availability, strength required, material durability, affordability, and availability. Despite the dependents, products derived from the materials deteriorate in value and strength due to physical, chemical and biological influence [1]. The deterioration eventually exceeds the shelf life with the last resort for the product being disposal. The latter is feasible if other waste management options such as reuse and recover are not feasible. Metal is one of the widely utilized materials. The use spans from tiny and simple tool to gigantic and sophisticated equipment and structures. This could be attributed to the superior durability and strength when compared with other materials like plastic and rubber, though on the high side in terms of cost [2]. The additional notable challenge in the utilization of metal-enriched materials is the significant contribution to environmental contamination due to the pronounced susceptibility to wear, rust and corrosion [3].

Chemicals in detergents, disinfectants, mineral lime, pesticides, fertilizers, herbicides, adhesives and from mining activities are equally sources of heavy metals [4-6]. One of the recipients of the contaminants is surface water. The contaminants from anthropogenic activities not only pollute the water source. Studies have also shown that heavy metals concentration in surface water is becoming a subject of concern $[7,8]$. Some of the

\footnotetext{
* Corresponding author, email: ajayibanjiademola@gmail.com

(C) 2015 Alma Mater Publishing House
} 
identified pollution sources are dump site close to water course [7,9], industrial waste discharged to surface water $[10,11]$ and leachate into the nearby stream from pesticides use to ward off insects and mineral fertilizer used as soil nutrient enhancer [12,13]. An elevated level of heavy metals in surface water poses a risk to aquatic lives. It could lead to the death of aquatic lives [14]. Another drawback in the application of such water for agricultural purposes is an accumulation of heavy metal in crop parts [15]. This might cause health risk when such crop is ingested by fauna and man. This should be of serious concern to farmers in arid and semi-arid regions of developing and underdeveloped countries, who see flowing water as a luxury. Suggested solutions to the challenges are enforcing laws to curb indiscriminate waste and wastewater discharge into a water course, location and relocation of dumpsite from surface water, monitoring activities around water bodies and surface water quality analysis and treatment of affected water sources before usage. The latter is very important in order to ensure stipulated standards are met prior to application. A number of water treatment methods such as precipitation, coagulation, membrane process and activated carbon exist. Though most have been discredited based on the high cost of the method and high volume cum low heavy metal concentration of effluents to be treated $[16,17]$. A suitable, effective and environment-friendly physico-chemical surface water treatment method is biosorption. This method is economically efficient because it employs biological materials such as cassava peel [18], maize tassel [19], rice straw [11] and wood waste [20] as biosorbents. Aside the merits, studies have shown that the precursors have effective treatability with respect to column bed height, adsorbent type, dosage and calcium content, sorbate flow rate and concentration, impregnation salt used and contact time [21-23]. Therefore, this study seeks to explore the usability of coconut husk char potential based on retention time in some heavy metals sequestration from mildly polluted surface water.

\section{METHODOLOGY}

The coconut was sourced from local farmers in Ilorin, Kwara State. The husk (Figure 1) was manually removed from the fruit, cleaned from external materials and weighed. Weighted husk mass was wrapped in double layers of aluminum foil before carbonization to ensure completely deoxygenated condition. The husks were subjected to different carbonization temperatures and times in an electric muffle furnace in order to obtain complete carbonization at optimum level with reference to good quality char. The temperatures at 30 mins carbonization time investigated were 300 and $350{ }^{\circ} \mathrm{C}$. Completely carbonized char produced at $350{ }^{\circ} \mathrm{C}$ (Figure 2) was washed in distilled water, filtered and oven dried at $105^{\circ} \mathrm{C}$ for $360 \mathrm{mins}$ in an electric oven dryer. The oven dried char was granulated after cooling, sieved to $1400 \mu \mathrm{m}$ size and stored. Char structure and elemental composition were investigated using SEM-EDX machine. One thousand and three hundred cubic centimeter capacity cylindrical polyvinyl chloride pipe reactor was used for the experiment. The choice of cylindrically shaped adsorber was to avoid pocket formed on the edges of the rectangular reactor during the test (personal observation).

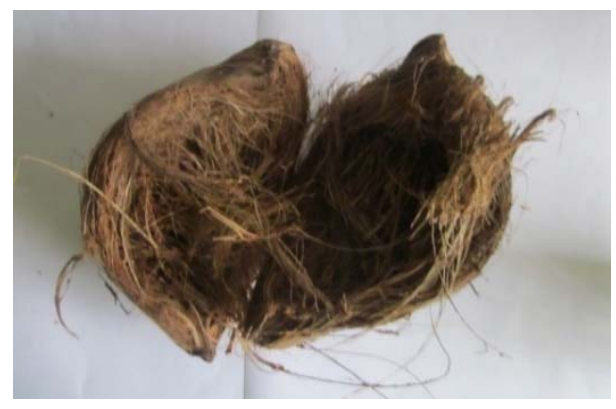

Fig. 1. Coconut husk.

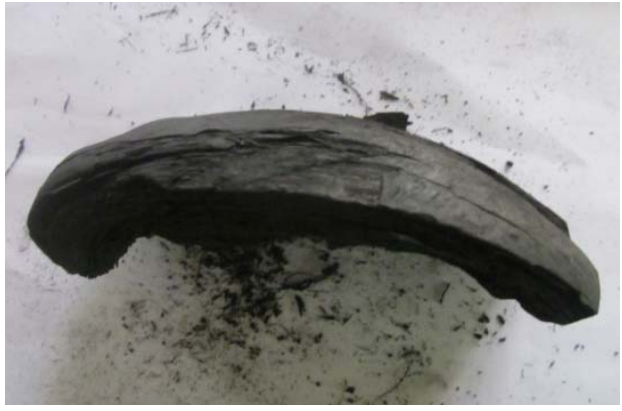

Fig. 2. Carbonized coconut husk.

The system has both inlet and outlet paths. The former receives untreated water from the temporary storage tank at a flow rate of $14 \mathrm{~mL} / \mathrm{min}$ and the outlet channel discharges the treated effluent. Fifty grams absorber (cotton wool) was carefully laid in the reactor to prevent the escape of adsorbent during discharge. The reactor was then loaded with $100 \mathrm{~g}$ of granulated coconut husk char before another $50 \mathrm{~g}$ of cotton wool was overlaid. Eighteen liters of water sample were collected under stringent condition from surface water channeled through Pipeline area, Tanke, Ilorin. The water is often utilized for ephemeral and annual crop cultivation by farmers especially during the peak period of the dry season in Ilorin, Nigeria. Horticulturist around the vicinity also service flowers with the water source. Influent collected from this source was temporarily stored in the tank before being introduced into the reactor. Samples of treated effluent from this experiment were taken after 30, 60, 90, 120 and 
150 mins retention time. Heavy metals investigated before and after treatment using standard method were lead, chromium, arsenic, cadmium, cobalt, aluminum, zinc, and copper. Biosorbent and surface water $\mathrm{pH}$ were equally investigated using standard method. Analyses were replicated and the mean values computed.

\section{EXPERIMENTAL CALCULATION}

The parameters investigated were removal efficiency, Freundlich and Langmuir models in linear representation and pseudo kinetic models after integration with boundary conditions. These are stated in equations (1) $-(6) . C_{o}$ represents the initial concentration of heavy metal in surface water sample before treatment $(\mathrm{mg} / \mathrm{L}) ; C_{t}$ denotes the concentration of heavy metal in effluent after treatment for a specific retention time $(\mathrm{mg} / \mathrm{L}) ; Q_{t}$ connotes the quantity of heavy metal adsorbed per adsorbent unit weight at a given contact time $(\mathrm{mg} / \mathrm{g}) ; V_{t}$ represents the volume of collected surface water in adsorption column at a definite detention time (1); $W_{b}$ is the mass of biosorbent (g); $t$ represents contact time in hrs. $Q_{m}$ represents the maximum adsorptive capacity of heavy metal $(\mathrm{mg} / \mathrm{g}) ; K$ is the Freundlich constant related to the extent of adsorption $(\mathrm{mg} / \mathrm{g}) ; n$ is the Freundlich parameter related to the adsorption intensity; $K_{L}$ is the Langmuir parameter related to the energy of adsorption $(\mathrm{L} / \mathrm{mg})$. Values of $K$ and $\mathrm{n}$ are constants deduced from the intercept and slope of plot of $\log Q_{t}$ against $\log C_{t} . K_{L}$ and $Q_{m}$ are obtained from the intercept and slope of plot of $C_{t} / Q_{t}$ against $C_{t}$. Constants $K_{Q}(\mathrm{~L} / \mathrm{min})$ and $K_{p}$ $(\mathrm{g} / \mathrm{mg} / \mathrm{min})$ are first and second-order pseudo kinetic rates. $Q_{e}$ represents the quantity of heavy metal adsorbed per adsorbent unit weight equilibrium $(\mathrm{mg} / \mathrm{g})$.

$$
\begin{gathered}
\text { Removal efficiency }=\left(C_{o}-C_{t}\right) C_{o} \times 100 \\
Q_{t}=\left(C_{o}-C_{t}\right) V_{t} / W_{b} \\
\log Q_{t}=\log K+(1 / n) \log C_{t} \\
C_{t} / Q_{t}=-1 /\left(Q_{m} \cdot K_{L}\right)+C_{t} / Q_{m} \\
\log \left(Q_{e}-Q_{t}\right)=\log Q_{e}-\left(K_{Q} / 2.3038\right) t \\
t / Q_{t}=1 /\left(K_{p} Q_{e}{ }^{2}\right)+t / Q_{e}
\end{gathered}
$$

\section{RESULTS AND DISCUSSION}

\subsection{Carbonization temperature and time}

Percentage mean weight loss after carbonization was 37.0 and $48.3 \%$ for 300 and $350{ }^{\circ} \mathrm{C}$ respectively. Statistically, there was no significant difference between weight loss in char at the carbonization temperatures ( $\mathrm{P}$ $<0.05$ ). Quality char was produced under a carbonization temperature and time of $350{ }^{\circ} \mathrm{C}$ and 30 mins respectively (Figure 2). The char was odorless and black-brown color. This is a physical pointer to a good carbonized product.

\section{2. $\mathrm{pH}$ changes in biosorbent}

Washing carbonized and granulated char generously in distilled water alters the $\mathrm{pH}$ value. Biosorbent $\mathrm{pH}$ value adjusted from 4.5 after impregnation and washing in distilled water to 5.6. The $\mathrm{pH}$ value is in line with [24] documentation for effective metal sorption. The process equally removes soluble inorganic ions aside dirt [16].

\subsection{Structural pattern and elemental composition}

EDX result in Figure 3 shows a high proportion of calcium ion with respect to other elements present. The presence of calcium suggests ion exchange mechanism other than biosorption could be responsible for metal diminution in mildly contaminated surface water [25]. Morphological structure of coconut char at $1.09 \mathrm{kx}$ and 50 $\mu \mathrm{m}$ magnification reveals plate-like structural pattern (Figure 4). The pattern is different from irregular structures observed for most biosorbents in terms of porosity $[19,26]$. This might be due to precursor employed. 


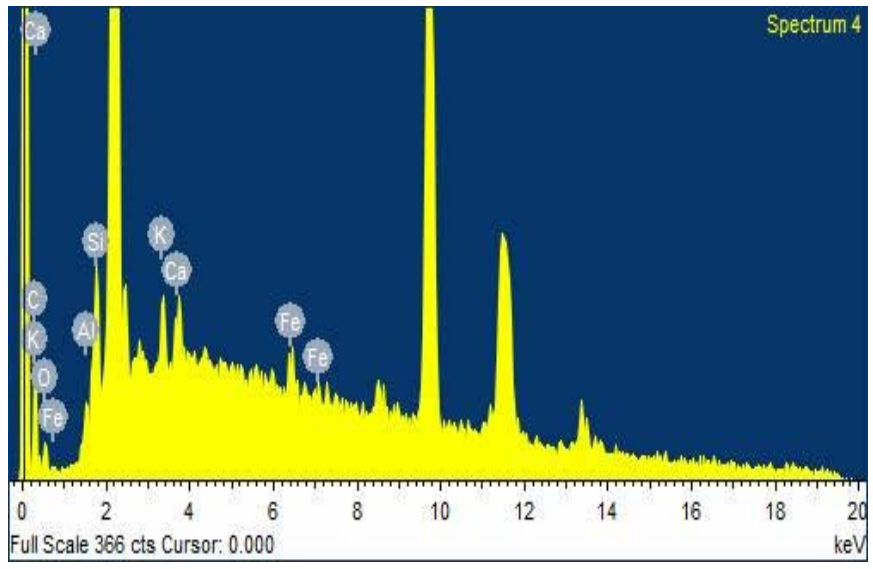

Fig. 3. EDX for carbonized coconut husk.

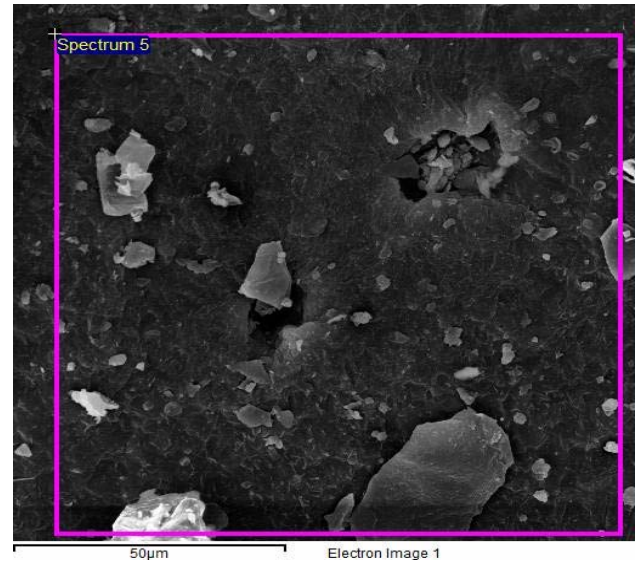

Fig. 4. SEM for carbonized coconut husk.

\subsection{Removal efficiency studies}

Mean values of treated surface water samples with respect to retention time are shown in Table 1. This is in line with the values obtained from surface water contamination study [7]. Contact time influenced removal efficiency though sorbent displayed different sorption tendencies with respect to heavy metals. In most cases, heavy metal removal increased with detention time. Zinc removal percentage from initial contact time through 30 mins increased by $36.67 \%$. Cadmium and aluminum demonstrated exceptionally rapid uptake at 30 mins retention time (Table 2). Eighty percent cadmium was sorbed at 30 mins detention time. Higher affinity was achieved with aluminum. This according to [24] is traceable to fast cadmium and aluminum ions mobility to the coconut husk char surfaces. This is an indication that the active sites have rapid uptake rate for cadmium and aluminum at 30 mins detention time. This suggests strong interaction between the adsorbate and adsorbent. Table 2 also shows that lead, chromium, zinc, copper and aluminum require extended detention time before complete adsorption is achieved under this experimental condition. Similar observation was suggested by literature [25, 27].

Table 1. Mean concentration of heavy metals in treated and untreated surface water.

\begin{tabular}{|l|c|c|c|c|c|c|}
\hline \multirow{2}{*}{$\begin{array}{l}\text { Heavy } \\
\text { metal }\end{array}$} & \multirow{U}{*}{$\begin{array}{l}\text { Untreated } \\
(\mathrm{mg} / \mathrm{L})\end{array}$} & \multicolumn{5}{|c|}{ Treated $(\mathrm{mg} / \mathrm{L})$} \\
\hline Lead & 0.130 & 0.087 & 0.057 & 0.037 & 0.030 & 0.023 \\
\hline Cadmium & 0.050 & 0.010 & 0.007 & 0.007 & 0.000 & 0.000 \\
\hline Chromium & 0.060 & 0.047 & 0.017 & 0.017 & 0.013 & 0.010 \\
\hline Arsenic & 0.020 & 0.013 & 0.000 & 0.000 & 0.000 & 0.000 \\
\hline Cobalt & 0.070 & 0.023 & 0.013 & 0.010 & 0.100 & 0.000 \\
\hline Zinc & 0.400 & 0.253 & 0.233 & 0.177 & 0.153 & 0.140 \\
\hline Copper & 0.500 & 0.367 & 0.317 & 0.283 & 0.250 & 0.233 \\
\hline Aluminum & 0.450 & 0.063 & 0.047 & 0.040 & 0.033 & 0.020 \\
\hline
\end{tabular}

Table 2. Removal efficiency for the biosorbent dose.

\begin{tabular}{|l|c|c|c|c|c|}
\hline \multirow{2}{*}{$\begin{array}{l}\text { Heavy } \\
\text { metal }\end{array}$} & \multicolumn{5}{|c|}{ Removal efficiency (\%) } \\
\cline { 2 - 6 } Lead & 30 mins & 60 mins & 90 mins & 120 mins & 150 mins \\
\hline Cadmium & 33.33 & 54.41 & 71.80 & 76.92 & 82.05 \\
\hline Chromium & 22.00 & 86.67 & 86.67 & 100.00 & 100.00 \\
\hline Arsenic & 33.33 & 72.22 & 72.22 & 77.78 & 83.00 \\
\hline Cobalt & 66.67 & 80.00 & 100.00 & 100.00 & 100.00 \\
\hline Zinc & 36.67 & 41.67 & 85.71 & 85.71 & 100.00 \\
\hline Copper & 26.67 & 36.67 & 43.83 & 61.67 & 65.00 \\
\hline Aluminum & 85.93 & 89.63 & 91.11 & 50.00 & 53.33 \\
\hline
\end{tabular}

\subsection{Isotherm models studies}

Adsorption isotherm data were consistent with Freundlich model with correlation coefficient values greater than 0.92. Therefore, Freundlich isotherm model satisfactorily gave a better description of adsorption process than Langmuir (Table 3). This equally implies the adsorption process is not monolayer [28, 29]. The low $\mathrm{k}$ value of 
zinc and copper is an indication of low adsorption intensity. This also confirms the low removal efficiencies for these contaminants (Table 2). The value of $\mathrm{n}$ less than unity connotes elevated sorption of sorbate at greater concentration [30]. The values of $\mathrm{n}$ for all the metals were within this range (Table 3).

Table 3. Isotherm model for coconut char biosorbent in heavy metal removal.

\begin{tabular}{|l|l|l|l|l|}
\hline \multirow{2}{*}{ Heavy metal } & \multicolumn{3}{|c|}{ Freundlinch } & Langmuir \\
\cline { 2 - 5 } & \multicolumn{1}{|c|}{$\mathrm{n}$} & \multicolumn{1}{|c|}{$\mathrm{R}^{2}$} & & $\mathrm{~K}$ \\
\hline Lead & 0.9983 & 0.2448 & 0.5033 & $\mathrm{R}^{2}$ \\
\hline Cadmium & 0.9248 & 1.8038 & 0.6639 & 0.0648 \\
\hline Chromium & 0.9612 & 5.5450 & 0.3429 & 0.5770 \\
\hline Cobalt & 0.9877 & 1.0361 & 0.6053 & 0.1745 \\
\hline Zinc & 0.9940 & 0.0359 & 0.7900 & 0.4523 \\
\hline Copper & 0.9999 & 0.0219 & 0.7750 & 0.8577 \\
\hline Aluminum & 0.9992 & 0.4629 & 0.8402 & 0.8060 \\
\hline
\end{tabular}

\subsection{Kinetic sorption studies}

There exist poor linear relationship between $\log \left(Q_{e}-Q_{t}\right)$ and $\mathrm{t}$, since regression coefficient values were less than 0.60 (Table 4). Therefore, the process is not pseudo-first order. On the contrary, good linearity exists between $\mathrm{t} / \mathrm{q}$ and $\mathrm{t}$. Heavy metals biosorption on coconut husk char fitted well into second order kinetic. Most correlation coefficient values were greater than 0.92 . According to [31], this indicates chemisorption mechanism involvement in the sorption process. The closely related experimental $\mathrm{Q}_{e}$ and calculated $\mathrm{Q}_{t}$ values from the plot $\mathrm{t} / \mathrm{q}$ against $\mathrm{t}$ confirms the linearity of the second order equation.

Table 4. Kinetic sorption studies for coconut char biosorbent in heavy metal removal.

\begin{tabular}{|l|l|l|l|r|c|}
\hline \multirow{2}{*}{ Heavy metal } & \multicolumn{2}{|c|}{ First order kinetic } & \multicolumn{3}{c|}{ Second order kinetic } \\
\cline { 2 - 6 } & $\mathrm{K}_{\mathrm{Q}}$ & $\mathrm{R}^{2}$ & $\mathrm{Q}_{\mathrm{e}}$ & $\mathrm{Q}_{\mathrm{t}}$ & $\mathrm{R}^{2}$ \\
\hline Lead & 0.5770 & 0.0562 & 0.9487 & 0.0030 & 0.0029 \\
\hline Cadmium & 0.3136 & 0.7225 & 0.9774 & 0.0019 & 0.0011 \\
\hline Chromium & 0.1921 & 0.4426 & 0.8072 & 0.0016 & 0.0015 \\
\hline Cobalt & 0.0538 & 0.1239 & 0.9872 & 0.0016 & 0.0015 \\
\hline Zinc & 0.0018 & 0.0042 & 0.9731 & 0.0068 & 0.0067 \\
\hline Copper & 0.0090 & 0.0207 & 0.9787 & 0.0070 & 0.0070 \\
\hline Aluminum & 0.2730 & 0.6289 & 0.9767 & 0.0099 & 0.0087 \\
\hline
\end{tabular}

\section{CONCLUSIONS}

Surface water contaminants sorption by $100 \mathrm{~g}$ of coconut husk char was considered in this study. The study shows that coconut husk char is an effective biosorbent in arsenic, cadmium and cobalt sorption from mildly polluted surface water in column experiment. Removal efficiency at 150 min retention time inspected for all the heavy metals except zinc and copper was greater than $80 \%$. Removal efficiencies of the heavy metals on coconut husk chars depend on contact time and heavy metal involved. Most kinetics of the heavy metals sorption on coconut husk char conforms to pseudo-second order equation $\left(\mathrm{R}^{2}>0.94\right)$. Chemical sorption of heavy metal was noticed in the process. Freundlich isotherm models well described the heavy metals sorption on the biosorbents $\left(\mathrm{R}^{2}>0.92\right)$.

\section{REFERENCES}

[1] Moncmanová, A., Environmental deterioration of materials, Faculty of Chemical and Food Technology, Slovak University of Technology, Bratislava, Slovak Republic, 2006.

[2] CIGR Handbook of Agricultural engineering, volume II, Animal production \& aquacultural engineering. Edited by CIGR-The International Commission of Agricultural Engineering, 1999.

[3] European Commission Project, Heavy metals in waste, Final report, 2002, p. $1-86$.

[4] WHO, Preventing disease through healthy environments. Exposure to cadmium: a major public health concern. Public health and environment. World Health Organization, Geneva, Switzerland, 2010.

[5] Danish environmental protection agency, Cadmium in fertilizers Risks from cadmium accumulation in agricultural soils due to the use of fertilizers containing cadmium: Model estimations, 2000, p. 1-89. 
[6] Ming-Ho, Y., Environmental toxicology: Biological and health effects of pollutants, CRC Press LLC, BocaRaton, USA, 2005.

[7] Nartey, V.K., Hayford, E.K., Ametsi, S.K., Assessment of the impact of solid waste dumpsites on some surface water systems in the Accra Metropolitan area, Ghana, Journal of Water Resource and Protection, vol. 4, 2012, p. $605-615$.

[8] Lambert, M., Leven, B.A., Green R. M., New Methods of Cleaning Up Heavy Metal in Soils and Water. Environmental science and technology brief for citizens, Hazardous substance research centre. Kansas State University, 2000, p. 1-3.

[9] Salami, L., Fadayini, M.O., Madu, C., Assessment of a closed dumpsite and its impact on surface and groundwater integrity: a case of Oke Afa dumpsite, Lagos, Nigeria, International Journal of Research and Reviews in Applied Sciences, vol. 18, no. 3, 2014, p. 222 - 230.

[10] Gyawali, S., Techato, K., Yuangyai, C., Effects of industrial waste disposal on the surface water quality of U-tapao river, Thailand, International Conference on Environment Science and Engineering, International Proceedings of Chemical, Biological and Environmental Engineering, vol. 3, no. 2, 2012, p. 109 - 113.

[11] Habuda-Stanić, M., Ravančić, M.E., Flanagan, A., A review on adsorption of fluoride from aqueous solution. Materials, vol. 7, 2014, p. $6317-6366$.

[12] Pearce, D., Koundouri, P., Fertilizer and pesticide taxes for controlling non-point agricultural pollution, World Bank's agriculture and rural development, environment, and water supply and sanitation departments and the international food policy research institute, www.worldbank.org/rural, 2003, p. $1-5$.

[13] Savc, S., An agricultural pollutant: Chemical fertilizer, International Journal of Environmental Science and Development, vol. 3, no. 1, 2012, p. $77-80$.

[14] Pan, X., Wang, J., Zhang, D., Sorption of cobalt to bone char: Kinetics, competitive sorption and mechanism, Desalination, vol. 249, 2009, p. 609 - 614

[15] Lawson, E.O., Physico-chemical parameters and heavy metal contents of water from the mangrove swamps of Lagos lagoon, Lagos, Nigeria, Advances in Biological Research, vol. 5, 2011, p. 8 - 21.

[16] Raikwar, M.K., Kumar, P., Singh, M., Singh, A., Toxic effect of heavy metals in livestock health, Veterinary World, vol.1, no. 1, 2008, p. 28-30.

[17] Chen, D.Z., Zhang, J.X., Chen, J.M., Adsorption of methyl tert-butyl ether using granular activated carbon, Equilibrium and kinetic analysis, International Journal of Environmental Science and Technology, vol. 7, no. 2, 2010, p. 235-242.

[18] Omotosho, O.A., Sangodoyin, A.Y., Production and utilization of cassava peel activated carbon in treatment of effluent from cassava processing industry, Water practice and Technology, vol. 8, no. 2, 2013, p. 215 - 224

[19] Sekhula, M.M., Okonkwo, J.O., Zvinowande, C.M., Agyer, N.N., Chaudhary, A.J., Dixed bed column adsoption of $\mathrm{Cu}(\mathrm{II})$ onto maize tassel-PVA beads, Chemical Engineering and Process Technology, vol. 3, no. 2, 2012 , p. $1-5$.

[20] Zheng, W., Sharma, B.K., Rajagopalan, N., Using biochar as a soil amendment for sustainable agriculture, 2010.

[21] Emmanuel, K.A., Veerabhadra, R.A., Comparative study of adsorption of Mn(II) from aqueous solutions on various activated carbon, E-Journal of Chemistry, vol. 6, no. 3, 2009, p. 693 - 704.

[22] Mahajan, G., Sud, D., Kinetics and equilibrium studies of chromium (VI) metal ion remediation by Arachis hypogeal shells-A green approach, Bioresource, vol. 6, 2011, p. 3324- 3338.

[23] Ijaola, O.O., Ogedengbe, K., Sangodoyin, A.Y., Kinetic study of water contaminants adsorption by bamboo granular activated and non-activated carbon, International Journal of Engineering and Technology Innovation, vol. 3, no. 4, 2013, p. $289-298$.

[24] Zhu, H., Wang, H., Wang, G., Kui, Z., Removal of fluorine from water by the aluminum-modified bone char. International Conference on Biology, Environment and Chemistry, vol. 1, 2011, p. 455 - 457.

[25] Lurtwitayapont, S., Srisatit, T. Comparison of $\mathrm{Pb}$ removal by various types of swine bone adsorbents. Environment Asia, vol. 3, no. 1, 2010, p. 32 - 38 .

[26] Ajayi-Banji, A.A., Morphological structure and elemental composition of locust beans husk, A project carried out at the Department of Agricultural \& Biosystems Engineering Department, University of Ilorin, Ilorin, Kwara State, Nigeria, 2014.

[27] Sangodoyin, A.Y., Ajayi-Banji, A.A., Utilization of abattoir solid wastes as biosorbents for surface water treatment, International Journal of Engineering Inventions, vol. 2, no. 11, 2013, p. $42-47$.

[28] Oluyemi, E.A., Adeyemi, F.A., Olabanji, I.O., Removal of $\mathrm{Pb}^{2+}$ and $\mathrm{Cd}^{2+}$ ions from wastewaters using palm kernel shell charcoal, Research Journal in Engineering and Applied Sciences, vol. 1, no. 5, 2012, p. 308 - 313.

[29] Giwa, A.A., Bello, I.A., Oladipo, M.A., Adeoye, D.O., Removal of cadmium from waste-water by adsorption using the husk of melon (Citrullus lanatus) seed, International Journal of Basic and Applied Science, vol. 2, no. 1, 2015, p. $110-123$. 
[30] Moreno, J.C., Gomez, R., Giraldo, L., Removal of Mn, Fe, Ni and Cu ions from wastewater using cow bone charcoal, Open Access Materials, vol. 3, 2010, p. 452 - 466.

[31] Dizadji, N., Anaraki, N.A., Nouri, N., Adsorption of chromium and copper in aqueous solutions using tea residue, International Journal of Environmental Science and Technology, vol. 8, no. 3, 2011, p. 631- 638. 